\title{
Evaluation of potential nirs to predict pastures nutritive value
}

\author{
I. Lobos ${ }^{1 *}$, P. Gou ${ }^{2}$ S. Hube ${ }^{1}$, R. Saldaña ${ }^{1}$ and M. Alfaro ${ }^{1}$ \\ ${ }^{I}$ National Institute for Agricultural Research, Remehue Research Centre, PO BOX 24-O, Osorno, Chile. ${ }^{2} I R T A$, Institut de Recerca \\ I Tecnologia Agroalimentaries, Centre de Tecnologia dels Aliments, Finca Camps i Armet, E-17121 Monells, Catalonia, Spain. \\ "Corresponding author: irislobos@hotmail.com
}

\begin{abstract}
This paper describes the capability of near infra-reflectance (NIRS) to predict the nutritional quality of pastures from southern Chile $\left(39^{\circ}-40^{\circ} \mathrm{S}\right)$. A Fourier transformed near-infrared (FT-NIR) method for rapid determination of dry matter (DM), crude protein (CP), in vitro digestibility (IVD) and metabolizable energy (ME) was used. Calibration models were developed between chemical and NIRS spectral data using partial least squares (PLS) regression and external validation. The coefficients of determination in calibration $\left(\mathrm{R}^{2} \mathrm{c}\right)$ were high varying between 0.89-0.99 and the root mean square errors of calibration (RMSEC) were low, ranging between 0.46-2.55 for the parameters analysed. The Residual Prediction Deviation (RPD) was higher than 2.5. Our results confirmed the convenience of using a wide range of samples applicability in the calibration set. Data also showed that the use of an independent set of samples for external validation increases the robustness of the models to predict unknown samples. Our results indicated RPD values higher than 2.5 which is the minimum recommended for this type of prediction. Thus, the result showed that NIRS was useful to estimate the nutritional quality of permanent pastures, and has a great potential to be used as a rapid decision tool for the studied analysis.
\end{abstract}

Keywords: Permanent pastures, animal nutrition, pastures composition, analytical methods

\section{Introduction}

Southern Chile $\left(39-42^{\circ} \mathrm{S}\right)$ is the most important area in the country for dairy production, accounting for $76 \%$ of the national milk production (ODEPA, 2012). These productive systems are mainly based on grazing of permanent pastures (Teuber, 2009).

New instrumental methods have been developed in the last decades to characterize the nutritional characteristics of animal feed used for dairy production.
One of these methods is the near-infrared spectroscopy (NIRS). The NIRS region is the wavelength range between 12000-4000 $\mathrm{cm}^{-1}$ in the electromagnetic spectrum. When a sample is analyzed, the radiant energy is absorbed selectively according to the specific vibration of the molecules presents, which produces an overtone in the spectrum (Conzen, 2006). Unlike most conventional analytical methods, NIRS is rapid, nondestructive, does not use chemicals, 
or generate chemical wastes requiring disposal and is multiparametric, i.e., several parameters can be determined simultaneously at the same measurement (Eldin, 2011).

This report is a short communication aimed to evaluate the potential of NIRS for the quantification of the nutrient composition of grazing of permanent pastures, for example for dairy production from southern Chile.

\section{Materials and Methods}

\subsection{Pasture sampling and chemical analysis}

The present study used 297 permanent pastures samples collected randomly in the period 2010-2011 in several farms located in southern Chile ( 39 to $42^{\circ}$ S). The sampling covered different seasons, growth stage, predominant species, soil types and fertility conditions. The forage obtained was representative of mixed permanent swards, comprising different proportions of grasses such as Lolium perenne, Agrostis sp, Holcus lanatus, Bromus valdivianus and Dactylis glomerata, and legumes such as alfalfa (Medicago sativa L.) and clovers (mostly Trifolium pratense $\mathrm{L}$. and $T$. repens $\mathrm{L}$.).

Each sample was homogenized and air dried at $60^{\circ} \mathrm{C}$ for $48 \mathrm{~h}$, grounded $(1 \mathrm{~mm})$, and analysed for the main nutritional parameters. Crude Protein (PC) was determined using the Kjeldahl method, AOAC (1970). In Vitro Digestibility (IVD) was determined by the Tilley and Terry method (1963) and the metabolizable energy (ME) was estimated using in vivo values, according to Garrido and Mann (1981). The dry matter content (DM) was determined by removing the residual water moisture at $105^{\circ} \mathrm{C}$, according to Harris (1970).

\subsection{NIRS analysis}

For NIRS analyses, 10-15g of dried and grounded sample was exposed to an electro-magnetic scan in the reflectance mode using a BRUKER FT-NIR MPA model (Bruker Optik GmbH, Ettlingen, Germany. Energy). Each spectral measurement was obtained from 32 scans performed at a wavenumber resolution of $16 \mathrm{~cm}^{-1}$

\subsection{Calibration and validation}

Partial least squares (PLS) regression was used to develop the calibration models. This method is based on information contained in the measured variables, so that they can be concentrated in a smaller number of variables, without losing relevant information. The regression was performed with these new variables, simplifying the calibration model and the interpretation of results. Additionally, regression was performed in an orthogonal space avoiding problems of collinearity between variables (Brereton, 1992). The chemometrical software OPUS ${ }^{\mathrm{TM}}$ version 6.0 (Bruker Optik GmbH, Germany) was used to create models, through the selection of wavelengths, mathematical pre-treatments and PLS factors, outlier determinations and PLS regression. From the total number of samples $(n=297)$, a first set of subsamples (n between 115 and 209 depending on the variable) were use for calibration to develop the regression models. A second set (n between 52 and 89 depending on the variable) was used for validation to evaluate the performance of the models developed. Calibration models were built correlating NIRS pre-processed spectral data with results from the chemical analysis for DM, CP, IVD and ME. The best models obtained were selected for each constituent based on the highest calibration coefficients $\left(\mathrm{R}^{2} \mathrm{c}\right)$, and the smallest root mean square error of calibration (RMSEC). In the validation process, the lowest root mean error of prediction (RMSEP) assess the overall error between modeled and reference values (Conzen, 2006). The coefficient of determination in prediction $\left(\mathrm{R}^{2} \mathrm{p}\right)$ and the residual predictive deviation (RPD) were also used as additional techniques to evaluate the predictive ability of the models. The RPD is a qualitative measure for the assessment of the validation results. 
Table 1. Range, mean, and standard deviation of chemical parameters and NIRS prediction models for the composition of permanents pastures samples used in the present study.

\begin{tabular}{|c|c|c|c|c|c|c|c|c|c|c|c|c|c|c|}
\hline \multirow[b]{2}{*}{ Parameters } & \multicolumn{7}{|c|}{ Calibration set } & \multicolumn{7}{|c|}{ Validation set } \\
\hline & $\mathrm{n}$ & Mean & Range & SD & RMSEC & $\overline{\mathrm{R}_{\mathrm{C}}^{2}}$ & RPD & $\mathrm{N}$ & Mean & Range & SD & RMSEP & $\mathrm{R}_{\mathrm{p}}^{2}$ & RPD \\
\hline$D M\left(g 100 g^{-1}\right)$ & 209 & 94.83 & $87.90-98.66$ & 2.72 & 0.90 & 0.89 & 3.1 & 85 & 94.81 & $87.60-98.66$ & 2.86 & 1.05 & 0.85 & 2.6 \\
\hline$C P\left(g 100 g^{-1}\right)$ & 208 & 20.19 & $9.60-31.96$ & 4.65 & 0.46 & 0.99 & 10.3 & 89 & 21.21 & $9.60-33.54$ & 5.78 & 0.57 & 0.99 & 10.3 \\
\hline IVD $\left(\mathrm{g}_{\left.100 \mathrm{~g}^{-1}\right)}\right.$ & 115 & 77.84 & $47.53-90.60$ & 9.44 & 2.55 & 0.93 & 3.8 & 60 & 78.71 & $54.20-89.80$ & 9.19 & 3.06 & 0.90 & 3.0 \\
\hline
\end{tabular}

RMSEC: root mean square error of calibration; RMSEP: root mean square error of prediction; $\mathrm{R}^{2} \mathrm{c}$ : coefficient of determination in calibration; $\mathrm{R}^{2} \mathrm{p}$ : coefficient of determination in prediction; RPD: residual prediction deviation.
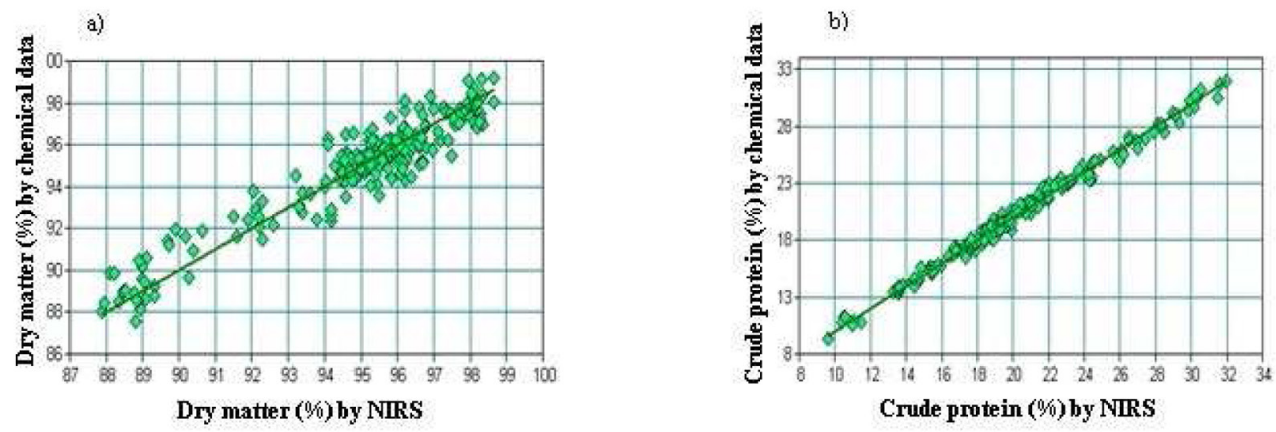

c)

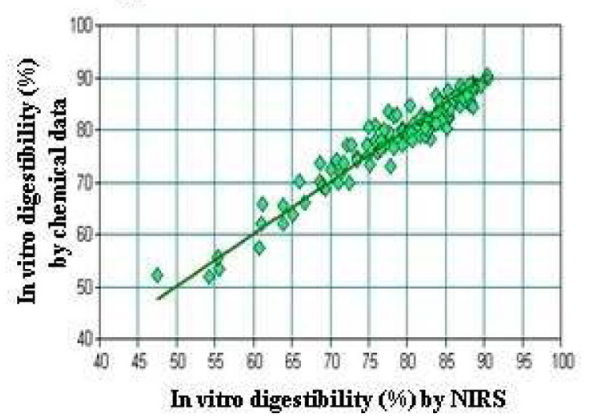

d)

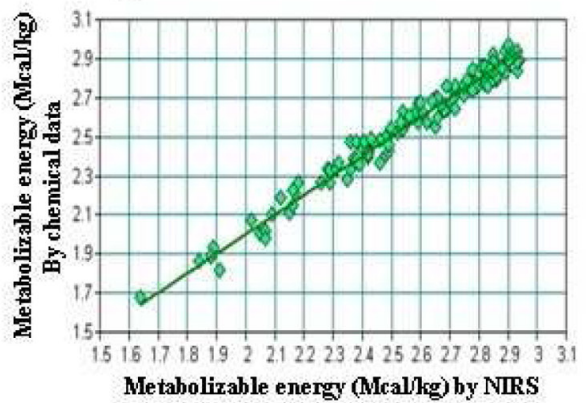

Figure 1. Models performance for the correlation of values obtained in the laboratory with respect to those predicted by NIRS for a) DM (\%), b) CP (\%), c) IVD (\%), d) ME (Mcal/Kg). 


\section{Results}

\subsection{Chemical composition and NIRS analysis}

There was a high variability in the nutrient components results of the samples determined by traditional chemical analysis (Table 1).

The composition predicted by NIRS corresponded closely with that of chemical analysis. Calibration coefficients of determination were higher than 0.89 . In the external validation, RMSEP was lower than $3, \mathrm{R}_{\mathrm{p}}^{2}$ was higher than 0.85 and RPD values above 3 were observed (Figure 1).

\section{Discussion}

\subsection{Chemical composition}

The high variation observed in the nutritional composition of samples analyzed is a positive factor for calibration when predicting the composition of variable forages, as the case of the present study. The chemical variation in pasture quality during the year of sample collection could be the direct result of variability in pasture's components (botanical composition), growth stage, climatic and management factors (Hopkins, 2000).

The nutritional values found agree with previous data reported for permanent pastures in the area of study. The average DM concentration found coincides with that obtained by Alomar et al. (2009) in herbage samples from Chile. The average CP concentration (Table 1) was consistent with those reported for dry and fresh pasture samples (20.5 and 20.6\%, respectively) (Alomar et al., 2003; 2009). The mean in vitro digestibility concentration obtained was higher than that obtained by Rojas et al. (2002) in samples of mixed grasslands. The average values for $\mathrm{ME}$ are in agreement with the values estimated by Alomar et al. (2009) and Rojas et al. (2002). These results showed that samples used in this analysis were werw representative of permanent pasture in southern Chile.

\subsection{NIRS calibration and validation}

The results showed that NIRS was a useful technique to predict plant nutrient contents as compared to conventional chemical analysis, making it a real alternative to traditional methods.

Crude protein was the parameter with the best prediction results. The error of calibration obtained in this case was lower than those obtained by Decruyenaere et al. (2009) and Fekuda et al. (2010) who obtained values of RMSEC 8.6 and 0.92, respectively Also, NIRS calibration for PC showed a RPD of 10.3, better than that of Alomar et al. (2009), with a value of 3.7 (Table 1). This could be related to the greater number of samples used in the present study (107 and 208 sample, respectively).

Metabolizable Energy showed a higher R2c than that obtained by Alomar et al. (2009) (0.97 versus 0.80, respectively). Also, the RPD value obtained in this study was 2.7 times higher than that obtained by Alomar (2009), probably because the greater number of samples used in the present study, as discussed previously.

The IVD model had a greater $\mathrm{R}^{2} \mathrm{c}$ than that found previously ( 0.93 and 0.82 , for the present and previous studies, respectively; Andrés et al., 2005). Also, in our study, the RPD value was higher than the recommended minimum for prediction (2.5; Williams and Sobering, 1996), confirming the robustness of our model.

In contrast to our previous findings, the result for $\mathrm{R}^{2} \mathrm{c}$ and RPD values for the DM model were lower than the values reported by Fekuda et al. (2010) and Alomar (2009). This could be related to the narrow range of maximum and minimum values found in the samples analysed for this parameter, in contrast to that of CP, ME and IVD (Table 1). 
The lower $\mathrm{R}^{2} \mathrm{p}$ values registered in our study, in addition to the wide range of applicability of the data used for calibration (maximum and minimum) in $\mathrm{CP}, \mathrm{ME}$ and IVD, as result of the variability in the samples used, resulted in high RPD values, showing that external validation is a better tool to test the performance of the prediction models to analyze unknown samples, in contrast to the cross validation method used previously for similar studies. In the cross validation method the samples from the calibration set are also used to test the viability of the models obtained, one at each time. The RPD values obtained in the present study for all parameters were higher than 2.5 which is the critical value used for the prediction of unknown samples (Williams and Sobering, 1996), showing that NIRS can be used as a quick tool to predict the nutritional composition of permanent pastures, based on DM, CP, ME and IVD. These results also confirm that NIRS is a real alternative to conventional methods for this purpose in southern Chile.

When calibrating NIRS for pasture quality determinations, our results confirmed the convenience of using a minimum of 100 samples for the calibration set, of a wide range of applicability, as this resulted in high RPD values. Also, data showed that the use of an independent set of samples for external validation increases the robustness of the models to predict unknown samples.

The analysis of the models obtained, confirmed the high predictive ability of NIRS to determine the nutritional composition of permanent pastures in southern Chile, expressed by DM, CP, IVD and ME.

\section{Acknowledgements}

Thanks the Fondo Nacional de Desarrollo Científico y Tecnológico (FONDECYT) post-doc grant n³120069.

\section{References}

Andrés, S., Giráldez, F.J., López, S., Mantecón, A.R., Calleja, A. 2005. Nutritive evaluation of herbage from permanent meadows by near-infrared reflectance spectroscopy: 1. Prediction of chemical composition and in vitro digestibility. J. Sci. Food Agric. 85, 1564-1571.

Alomar, D., Fuchslocher, R., De Pablo, M. 2003. Effect of preparation method on composition and NIR spectra of forage samples. Anim. Feed Sci. Technol. 107, 191-200.

Alomar, D., Fuchslocher, R., Cuevas, J., Mardones, R., Cuevas, E. 2009. Prediction of the composition of fresh pastures by Near Infrared reflectance or interactance-reflectance Spectroscopy. Chilean J. Agric. Res. 69, 198-206.

Association of Official Agricultural Chemist (AOAC). 1970. Official methods. 1015 p. William Horwist, Washington, DC, USA.

Brereton, R.G. 1992. Chemometrics: applications of mathematics and chemometrics, illustrated by case studies. Elsevier. Amsterdam. The Netherlands.

Conzen, J.P. 2006. Multivariate calibration, a practical guide for developing methods in the quantitative analytical chemistry. Ettlingen, Germany: BrukerOptik GmbH.

Decruyenaere, V., Lecomte, P.H., Demarquilly, C., Aufrere, J., Stilmant, D., Buldgen, A. 2009. Evaluation of green forage intake and digestibility in ruminants using near infrared reflectance spectroscopy (NIRS): Developing a global calibration. Anim. Feed Sci. Technol. 148, 138 156.

Eldin, A. 2011. Near Infra Red Spectroscopy, Wide Spectra of Quality Control, In Tech Publishers, Croatia, 238-248 p. 
Fekadu, D., Bediye, S., Kehaliw, A., Daba, T., Kitaw, G., Assefa, G. 2010. Near Infrared Reflectance Spectroscopy (NIRS) for determination of chemical entities of natural pasture from Ethiopia. Agr. Biol. J. N. Am. 1, 919-922.

Garrido, O., Mann, E. 1981. Composición química, digestibilidad y valor energético de una pradera permanente de pastoreo a través del año. Thesis, Universidad Austral de Chile, Chile. 61 p.

Harris, L. (1970). Nutrition research techniques for domestic and wild animals. An International Record System and Procedures for Analyzing Samples. Animal Science Department. Utah State University. Logan, Utah.

Hopkins, A. 2000. Grass Its Production and Utilization. (3th. eds. Blackwell Science), 440 p.

ODEPA, 2012. Boletín de la Leche. Publicación de la oficina de Estudios y Políticas Agrarias (ODEPA) del Ministerio de Agricultura, Gobierno de Chile, 15 p.
Rojas, C., Romero, O., Barrientos, L. 2002. Beef production with yellow serradella (Ornithopuscompressus L.) and subterranean clover (Trifoliumsubterraneum L.) under dryland conditions in the IXth Region, Chile. Agric. Téc.62, 519-529.

Tilley, J. A., Terry, R. A. 1963. A two-stage technique for the in vitro digestion of forage crop. J. Brit. Grassland Soc. 18, $104-111$.

Williams, P.C., Sobering, D.C. 1996 How do we do it: a brief summary of the methods we use in developing near infrared calibrations. In: Near Infrared Spectroscopy: the future waves. Davies A.M.C., Williams P. (Eds.). NIR Publications, Chichester, UK, pp: 185-188. 